Estudios sobre el Mensaje Periodístico ISSN-e: 1988-2696

http://dx.doi.org/10.5209/ESMP.55613

\title{
Uso de Twitter en el Periodismo Científico. Caso: El Nacional y El Universal en Venezuela (septiembre-octubre de 2014)
}

\author{
Herly Alejandra Quiñónez Gómez; Moisés Francisco Sánchez Colmenares²
}

Recibido: 31 de enero de 2016 / Aceptado: 5 de septiembre de 2016

Resumen. Twitter ha logrado activar y fortalecer a la ciberciudadanía e incidir en un cambio en el quehacer periodístico. Esta investigación se plantea como objetivo describir el uso de Twitter por parte de los periodistas que cubren la fuente científica y tecnología en los diarios más antiguos de Venezuela: El Nacional y El Universal durante los meses de septiembre y octubre de 2014. La investigación corresponde a un estudio documental-descriptivo. Los resultados obtenidos muestran la poca presencia de noticias relacionadas con la ciencia en Twitter, un incremento de la labor periodística con el servicio público, escaso uso de elementos multimedia y alta presencia de los ciudadanos como fuente informativa por encima de la gubernamental. Se concluye que los periodistas están participando con frecuencia media en la generación de contenidos vinculados con la ciencia y tecnología.

Palabras clave: Periodismo científico; Twitter; redes sociales.

\section{[en] Use of Twitter in Science Journalism. Case: El Nacional and El Universal in Venezuela (September-October 2014}

\begin{abstract}
Twitter has managed to activate and strengthen the cyber citizenship and influence a change in the journalistic work. This research therefore seeks to describe the use of Twitter by journalists covering science and technology source in the oldest newspapers in Venezuela: El Nacional and El Universal during the months of September and October 2014. The investigation corresponds to a descriptive study documentary. The results show the low presence of science-related news on Twitter, an increase of journalism to public service, low use of multimedia elements and high presence of citizens as an information source over government. We conclude that journalists are participating with the average frequency content generation linked with science and technology.
\end{abstract}

Keywords: Scientific journalism; Twitter; social networks.

Sumario. 1. Introducción. 2. El problema; 2.1. Antecedentes. 3. Fundamentos teóricos; 3.1. Periodismo científico; 3.2. Redes Sociales; 3.3. Twitter; 3.4. Ciberperiodistas. 4. Metodología. 5. Análisis de resultados; 5.1 Periodista El Nacional; 5.2. Periodista El Universal. 6. Conclusiones. 7. Referencias bibliográficas.

Cómo citar: Quiñónez Gómez, Herly Alejandra y Sánchez Colmenares, Moisés Francisco (2017): "Uso de Twitter en el Periodismo Científico. Caso: El Nacional y El Universal en Venezuela (septiembre-octubre de 2014)", en Estudios sobre el Mensaje Periodístico 23 (1), 553-568.

\footnotetext{
$1 \quad$ Universidad de Los Andes (Venezuela)

E-mail: gomezh@ula.ve

2 Universidad de Los Andes (Venezuela)

E-mail:mfsc_2011@hotmail.com
} 


\section{Introducción}

En la actualidad, las redes sociales juegan un papel importante en la Comunicación Social, ya que forman parte esencial de los ciudadanos cuyo deseo de adquirir conocimientos e información se ve satisfecho a través de la consulta de medios como Facebook o Twitter, no sólo a través de una computadora, sino de sus dispositivos móviles. A lo largo de esta investigación se analiza el uso que los periodistas de los diarios El Nacional y El Universal, de Venezuela, dan a Twitter, para informar sobre ciencia y tecnología durante los meses septiembre y octubre del año 2014.

Con el uso de las redes sociales lo que está planteado realmente es una transformación en el quehacer periodístico, ya que en este tiempo de redes sociales, de comunicación 2.0, son los ciudadanos quienes informan a través de estos medios convergentes. Esta investigación se plantea como interrogante ¿Qué uso le están dando a Twitter, para informar a la población sobre los avances de ciencia, tecnología e innovación los diarios El Nacional y El Universal en Venezuela? La respuesta se obtiene mediante una investigación documental-descriptiva que será abordada en este trabajo a través de un análisis de contenido.

En este estudio se aborda el uso que dan los periodistas que cubren la fuente científica en dos medios nacionales como lo son El Nacional y El Universal a Twitter como herramienta que facilita el acceso de los usuarios al conocimiento científico, permitiendo avanzar o profundizar aún más en una cultura de carácter científico y tecnológico para entender el proceso de cambio por el que transita el mundo globalizado en lo que a comunicación social se refiere. En el texto se plantean el problema y los objetivos, así como los fundamentos teóricos, metodológicos, los resultados y finalmente, las conclusiones.

\section{El problema}

La ciencia y la tecnología han ganado un gran terreno en el mundo moderno. Hoy día la ciudadanía se mueve en torno a las innovaciones tecnológicas comunicativas que van marcando la dirección hacia la cual se va a dirigir la sociedad. Desde esa concepción "la ciencia y la tecnología son la médula del mundo actual" (Ferrer, 2003: 9).

Las palabras difusión y divulgación parecen estar íntimamente relacionadas cuando se habla de investigación. Sin embargo, los resultados que estas investigaciones arrojan no tendrían razón de ser si no son dadas a conocer a las otras comunidades científicas o a quienes son más reacios en temas de ciencia y tecnología: las audiencias. Citando un estudio que realizó el Gobierno del Principado de Asturias, la divulgación científica está siendo tomada a través de la web como una forma de difusión de toda una amalgama de investigaciones y avances en el ámbito de la ciencia, orientada hacia la experiencia de la Web 2.0 de forma más institucional (García y Fernández, 2011: 5).

Parafraseando a García y Fernández (2011: 8) no se debe olvidar que el fin último de la ciencia es generar progreso a la sociedad, ésta viene a ser la parte final del trabajo investigador que, además, hay que resaltar es "cierto, probado y aporta nuevas ideas".

El acercamiento que la comunidad científica tiene a raíz del uso frecuente de la Internet genera entre los investigadores un contacto habitual con científicos y comu- 
nidades científicas en todas partes del mundo a través de la red de redes, es decir, no se limita simplemente a un espacio local, sino que trasciende en compartir la información con otros colegas del ámbito científico en cualquier rincón del planeta que tenga acceso a Internet.

El periodismo intenta explicar a las comunidades no científicas el quehacer científico. No obstante, hay que asegurarse primero que los periodistas que cubren estas informaciones comprendan la magnitud del acontecimiento científico para que, con exactitud y con lenguaje periodístico, lo transmitan al público en general. En este punto se encuentra la afirmación hecha por Gregori (2004):

Dada la complejidad del lenguaje científico, estos profesionales de la información necesitan contar con la colaboración directa de una no menos extensa red de científicos especialistas en las diferentes ramas del saber. Este grupo de expertos se encargaría, a su vez, de matizar la importancia de las novedades científicas que llegan a la mesa de los periodistas y, además, podrían aclarar o ampliar esta información con la rapidez que requiere su difusión a través de los medios de comunicación (Gregori, 2004: 27).

Calvo Hernando, citando a Rithchie Calder, asegura que "la ciencia es la eterna interrogación de la naturaleza por el hombre” (Pérez, 2007: 2). En este sentido, el ser humano está dando respuesta, cada vez más, a las interrogantes que plantea su entorno social, de modo que la ciencia deja de serle abstracta y alejada para pasar a formar parte inherente de su vida.

Desde la perspectiva de Manuel Calvo Hernando (1997) "la idea básica (del periodismo científico) es llevar la ciencia al público en general, para atender así el requerimiento social de información científica para todos" (Calvo, 1997: 16).

Tiene que poseer un bagaje suficiente de conocimientos sobre los hechos, conceptos, estructuras conceptuales y habilidades que le permitan seguir aprendiendo lógicamente. Esta persona será capaz de apreciar el valor de la Ciencia y la Tecnología y de entender a su vez sus limitaciones (Cazaux, 2010: 21).

El periodista científico se dedica a divulgar de manera ecuánime algún hecho científico acaecido en la actualidad inmediata, pero de una manera en que, sin perder su sentido estricto, llegue a la sociedad con un lenguaje sin tantos artilugios técnicos. "El periodismo científico es el puente que permite a los ciudadanos alcanzar hoy este conocimiento y entender el progreso de la ciencia y del método científico" (Ferrer, 2003: 9). Importante, entonces, insistir en el papel del periodista científico a raíz de la conceptualización dada; será entonces como el instrumento que logrará sembrar en la sociedad una cultura científica más apta y consecuente con los cambios a los que se enfrenta la comunidad globalizada.

Con la aparición de las redes sociales en la comunicación global, la ciencia ha dejado de ser un espectro casi intocable por la sociedad. Ahora, toda comunidad científica cuenta con, al menos, una red social por medio de la cual dan a conocer todos los adelantos de sus investigaciones.

El periodismo está asistiendo a un cambio total de paradigma (Noguera, 2010) en cuanto a la divulgación de la información y, por ende, debe flexibilizar la forma 
en que es entendido en los ámbitos comunicacionales. Si se dice que está asistiendo a este cambio de paradigma no es para que se quede observando desde la distancia sino para que forme parte del proceso y se adentre al cibermedio como espacio de difusión-divulgación de información.

Las redes sociales no sólo hacen referencia a alguna red interconectada a través de la Internet sino a todas aquellas relaciones interpersonales entre individuos en distintos ámbitos de la vida social, por ello, la importancia que ha tomado esta nueva realidad en la contemporaneidad, y es que ahora no solo es una relación personal, sino que también puede referirse a relaciones sociales sin que haya algún tipo de contacto físico.

En sentido amplio, una red social es una estructura social formada por personas o entidades conectadas y unidas entre sí por algún tipo de relación o interés común. Las redes sociales son parte de nuestra vida, son la forma en la que se estructuran las relaciones personales, estamos conectados mucho antes de tener conexión a Internet (Ponce, 2012: 18).

Se observa en la web una convergencia de medios que facilitan en el caso de Twitter la "micro-narrativa periodística" (Noguera, 2010), mientras que la red social Facebook, es un conglomerado de posibilidades en las que se puede profundizar con mayor ahínco la divulgación de la ciencia y la tecnología de modo que pueda ser entendida por la comunidad no especializada en este tipo de informaciones, valiéndose de "microblogging, vídeo, blogging, imágenes y otras formas comunicativas. La multitarea y la remezcla de narrativas es la rutina de estos espacios agregadores por naturaleza" (Noguera, 2010).

En esta realidad, el periodista científico, como señala Pérez (2007: 2):

Tiene la responsabilidad de recodificar el mensaje de la fuente científica y construir un mensaje para un público no especialista; entendiendo como periodismo, la captación y tratamiento, escrito, oral, visual o gráfico, de la información en cualquiera de sus formas y variedades.

En esta investigación se formula la siguiente inquietud: ¿Cómo están usando las redes sociales los periodistas que cubren la fuente científica en los diarios venezolanos El Nacional y El Universal durante los meses de septiembre y octubre de 2014? El problema se sistematiza mediante las siguientes interrogantes: ¿Qué tipo de informaciones emiten los periodistas a través de sus perfiles en la red social Twitter?, ¿cómo usan los periodistas de El Nacional y El Universal la red social Twitter? y ¿cuál es el tratamiento que dan los periodistas a sus informaciones científicas para ser leídas en Twitter?

Desde el problema se plantea como objetivo general: describir cómo usan la red social Twitter los periodistas que cubren la fuente científica en los diarios venezolanos El Nacional y El Universal durante los meses de septiembre y octubre de 2014 y los objetivos específicos son: analizar las informaciones que emiten los periodistas de El Nacional y El Universal en sus perfiles en Twitter, describir el uso del Twitter para la divulgación de información científica y tecnológica los periodistas de $\mathrm{El} \mathrm{Na}$ cional y El Universal y describir el tratamiento que debe darse a las informaciones científicas para ser leídas en Twitter. 


\subsection{Antecedentes}

Antón y Alonso (2015) decidieron comprobar si existe disparidad entre los intereses de la agenda temática (agenda setting) y las tendencias de Twitter. El estudio lo hicieron comparando las tendencias con las portadas de ediciones digitales de tres medios de comunicación españoles. Concluyen que las ediciones digitales de los medios nacionales tratan el $41,4 \%$ de los temas que a los usuarios de Twitter les interesa. Dicha investigación guarda relación con la investigación por el objeto de estudio: Twitter y periódicos.

Herrero (2012), en "El periodismo en el siglo de las redes sociales", busca exponer y analizar los procesos de cambios que ha producido la aparición de las redes sociales en el periodismo y cuáles han sido, al criterio de Herrero-Curiel, los protagonistas principales en este proceso. Su aporte a la investigación está relacionado con la importancia de las redes sociales en el periodismo de hoy y cómo pueden contribuir con el procesamiento y divulgación de la información.

En tal sentido, Ponce, I. (2012) publicó "Redes Sociales". En el se expone cómo las redes sociales a través de la Web 2.0 se han convertido en un boom, un fenómeno global y de cómo han pasado a formar parte importante de las relaciones personalessociales. El anterior estudio, contribuye de manera clara y concisa para precisar todo lo relacionado a redes sociales, ofreciendo un panorama completo sobre el tema.

Harris, Ríos y Páez (2011) en "El periodista venezolano en Twitter" plantean un perfil del periodista venezolano con respecto al uso de la red social Twitter. Se trata de un proyecto descriptivo y analítico, con un diseño no experimental. Este estudio se relaciona con la investigación porque explica el el uso que periodistas venezolanos dan a esta red social.

García y Fernández (2011) en "Difusión y divulgación científica en Internet" señalan la revolución que ha causado la Internet en el ámbito de la investigación sobre ciencia, hacen, además, toda una radiografía de la web para ubicar a los cibernautas en los lugares específicos donde pueden colgar sus investigaciones.

\section{Fundamentos teóricos}

\subsection{Periodismo científico}

El periodismo científico y las redes sociales vienen a constituir el problema de estudio, pero más allá de eso, es importante definir lo que realmente ocurre en una sociedad tan mediatizada como la actual. Hoy día está en pleno auge la comunicación a través de las redes sociales, entendida, en este caso, como el proceso mediante el cual, quienes componen una "red social" se comunican. Definitivamente si hay algo certero en este proceso investigativo es que la comunicación a raíz de la Internet y las TIC, cambió.

En los últimos años hemos asistido a un cambio radical en el modelo comunicativo. Esta transición no solo ha afectado a los usuarios de internet, que cada vez participan más en el nuevo entorno comunicativo, sino que los propios periodistas han tenido que incluir en sus rutinas diarias otras herramientas nacidas del desarrollo de la web 2.0 (Herrero C, 2012: 114). 
Si el periodismo ha asistido a un cambio radical en el modelo de la comunicación, es importante adaptarlo a este cambio, pero ello se logra a través del estudio de las potencialidades que ofrecen los nuevos espacios. Al estar inmersos en ellos y no conocerlos certeramente resultaría que en vez de ayudar o facilitar la labor periodística sencillamente estaría sepultando el trabajo, quizá, de muchos años. Parte del proceso actual de la comunicación en redes sociales coadyuvan al periodista en lo que concierne a encontrar fuentes. Hace al menos unos lustros, para conseguir una cita con una fuente informativa, el periodista debía realizar un arduo trabajo de seguimiento para obtenerla. En la actualidad, debe seguirlo solo a través de las redes sociales, y logrará, en menor tiempo, tal vez, la cita o las respuestas oficiales a sus cuestionamientos.

Sin embargo, como señala Herrero-Curiel (2012: 115):

El periodista debe ser capaz de filtrar, comprobar y acreditar esos nuevos contenidos que se generan en los Social Media y llevar a cabo un trabajo informativo completo y eficaz, sin olvidar la veracidad y el rigor que debe desprenderse de cualquier noticia.

Llevando esta idea al plano del periodismo científico, el rigor de la fuente científica debe permitir que los periodistas utilicen estos medios de comunicación para dar conceptualizaciones sencillas a los lectores, con el objeto de que el periodismo científico cumpla con una de sus principales tareas de informar a la comunidad en general de los avances y adelantos que en esta materia se están dando en el país o fuera de él y cómo esto favorece a la sociedad o en su defecto acarrea algún tipo de consecuencias negativas en el porvenir social.

Quiñónez (2015) dice que el periodismo científico tiene varias funciones: informar, interpretar y opinar sobre ciencia y tecnología; promover y divulgar el avance de las ciencias, fortalecer la cultura científica y tecnológica para el desarrollo y crear formas narrativas y divulgativas para la información científica y tecnológica.

En este sentido, se puede observar que el rol del comunicador científico, no es simplemente el de informar, sino que se convierte en un orientador con un papel clave, adquiere cierto protagonismo a la hora de enlazar ciencia y sociedad y para ello, en este siglo globalizado, cuenta con la ayuda de las redes sociales, grandiosas plataformas que permiten al periodismo expandir sus fronteras, ir más allá, ya que como lo plantea Herrero-Curiel (2012: 116):

Antes el lector consumía los textos sin mucha capacidad de acción, ahora sus comentarios, búsquedas o publicaciones pasan a formar parte del contenido mediático en numerosas ocasiones.

\subsection{Redes sociales}

Las redes sociales, sin duda han supuesto un cambio desde su aparición. Según Lozares (1996: 104): "La teoría de redes es deudora de diferentes corrientes de pensa- 
miento y teorías: antropológica, psicológica, sociológica y también matemática". Es común encontrar estudios que señalan que esta teoría de redes haya sido estudiada por diferentes disciplinas sociales.

El estudio de las redes sociales ha permitido alcanzar avances cuantitativos en lo que respecta a las relaciones entre individuos que comparten un mismo criterio o quienes lo refutan. Durante los años setenta y ochenta, la teoría de redes alcanza un culmen en las investigación, con avance en lo metodológico, teórico y conceptual. "Las Redes Sociales pueden definirse como un conjunto bien delimitado de actores -individuos, grupos, organizaciones, comunidades, sociedades globales, etc. - vinculados unos a otros a través de una relación o un conjunto de relaciones sociales" (Lozares, 1996: 108).

Aunque lo anterior sigue siendo un concepto muy general y tiende a ser bien aplicado, en la actualidad, al hablar de redes sociales no solo se está refiriendo a intereses de un conjunto determinado de individuos en la sociedad palpable, sino también, "se ha convertido en una expresión del lenguaje común que asociamos a nombres como Facebook o Twitter" (Ponce, 2012: 15). Ponce, va más allá de esta realidad física y la lleva a un espacio infinito, el ciberespacio. Sin embargo, ella misma aclara que a pesar de que en estos tiempos, al hablar de "red social" se haga referencia a las redes digitales, el estudio de éstas vienen de décadas atrás por diferentes disciplinas científicas.

La aparición de las Social Media, en contraposición a los Mass Media, representa un fenómeno social. En tiempos de los "Medios de Comunicación Masivos" nunca hubo una interacción tan rotunda con quienes estaban del otro lado de la pantalla, del papel o de la radio, a diferencia de las nuevas tecnologías que confluyen en una comunicación, directa y en tiempo real, acortando las distancias y las fronteras que separan a los países.

\subsection{Twitter}

Para Cobos (2010) Twitter — www.twitter.com — que se traduce en trinar o gorjear, es una red social de microblogging que surgió en Estados Unidos en el año 2006 y que permite a sus usuarios comunicarse y relacionarse con sus seguidores a través de los trinos con 140 caracteres. Agrega que la pregunta clave del servicio es "¿Qué está pasando?"

Twitter podría definirse como una plataforma de comunicación bidireccional, de microblogging, con naturaleza de red social ya que permite que el usuario elija con quién relacionarse. En una entrevista realizada por el diario "El Pais" de España en el año 2008 a Jack Dorsey, considerado el padre del Twitter, este asegura que: "Con Twitter estamos en contacto diario, sabemos qué estamos haciendo uno y otro sin necesidad de hablar por teléfono, la gente se suelta más, es una manera de estar más unidos, de compartir más cosas".

Las características físicas de Twitter se basan en una relación entre "seguidores" (followers) y "seguidos" (followed). Los seguidores son aquellas cuentas de Twitter que siguen al usuario. Los seguidos son a quienes el usuario sigue. Existe una línea de tiempo real (timeline), en la que aparecen los tuits de las personas a quien el usuario sigue, también tiene la opción de bloquear y, recientemente, silenciar usuarios; todo en una perfecta cronología.

Orihuela (2011), citado por Alconchel (2013: 28), señala: 
Las características del modelo comunicativo del Twitter son: 1. Asimétrico: una red social de relaciones (seguir/ser seguido) en la que no se requiere el consentimiento mutuo entre los usuarios. 2. Breve: un formato de escritura limitado a 140 caracteres por mensaje. 3. Descentralizado: una arquitectura variable multipuntomultipunto definida por las decisiones de cada usuario. 4. Hipertextual: un entorno de lecto-escritura en el que cada mensaje contiene enlaces por defecto (el usuario y el enlace permanente del mensaje) y en el que el uso del símbolo @ (arroba)y del signo \# (numeral) genera enlaces de manera automática. 5. Social: un conjunto de comunidades y relaciones definidas por cada usuario. 6. Viral: una plataforma que facilita la circulación y multiplicación de los mensajes.

Cuando una noticia aparece en las redes sociales es tentador para un periodista apurarse en difundirla para que sea el primero en dar la "primicia" sin embargo, como ya se señaló existen cuentas que se encargan de producir informaciones falsas. Algunos estudiosos de la comunicación sugieren varios pasos para verificar este tipo de contenidos antes de contribuir con su difusión.

Para Muñoz (citado por Cobos, 2010: 7) Twitter tiene los siguientes usos periodísticos:

1. Fuente de información: Twitter puede compararse con leer un medio de comunicación [...] 2. Inspiración para reportajes: [...] se pueden encontrar tendencias sobre las que se puede profundizar e investigar. 3. Twittervistas: permite hacer entrevistas [...] y (ofrece) brevedad, accesibilidad y asincronía [...] 4. Verificación de información: se puede indagar sobre la precisión de un dato o contrastar informaciones. 5. Noticias urgentes: al ser un medio rápido genera alerta temprana sobre las noticias. 6. Crowdsourcing: permite recopilar información a través de consultas públicas. 7. Termómetro sobre el interés de un tema: con las tendencias se puede conocer el interés social.

Harris, Ríos y Páez (2011) citando a Cavelier (2010: 98) señala que "Venezuela se encuentra entre los países con más usuarios de Twitter al igual de Brasil, Chile y México". Harris et al. (2011) aseguran que el 60\% de los mensajes que retuitea el periodista venezolano son fuentes oficiales y el $40 \%$ son mensajes de otros periodistas. Twitter es una herramienta dotada de inmediatez que permite al género informativo publicar y dar adelantos de noticias que serán abordadas con mayor profundidad en los sitios web de periódicos o canales de televisión a los que se accede a través de un link que está dentro de la micro información.

Zamarra (2015) asegura que la red social preferida por los periodistas es Twitter, porque es la manera más directa de llegar a la sociedad. Diariamente los periodistas difunden las informaciones a través en un tuit que enlaza esa noticia a la web y que existen algunos casos donde la actividad es muy elevada.

\subsection{Ciberperiodistas}

En la profesión periodística entra en juego el llamado ciberperiodismo. La relación del comunicador social con esto del ciberperiodismo está ligada a la nueva manera de enfrentar la comunicación en el mundo globalizado. Varios autores sostienen que 
los emporios de la comunicación entendieron que Internet, con todos sus atributos, es un factor estratégico y multidisciplinar para su futuro.

Para Chirinos y Torres (2013: 3): "La adaptación del periodista al ciberperiodismo constituye un proceso cuyo norte y acción se orientan hacia la comprensión y asimilación de la tecnología, de las TIC y por supuesto, del modelo periodístico emergente".

Una de las características del periodismo en general es la inmediatez, y el ciberperiodismo cumple con esta función al poseer este tipo de escenarios de comunicación. Claro está que para acceder a estas informaciones las audiencias deben contar con conexión a internet y debido a los adelantos tecnológicos la aplicación Twitter se puede revisar desde celulares hasta ordenadores de mesa.

Chirinos y Torres (2013:4) señalan que:

La relación del periodista con el Ciberperiodismo implica investigar en el ciberespacio para detectar y abordar fuentes acreditadas en la Red; desarrollar nuevas rutinas profesionales que comienzan por saber para cuál redacción se trabaja (física, digital o ambas), su relación con los destinatarios de la información, el medio y los contenidos, teniendo como norte la inmediatez y a la ciberaudiencia.

Los autores plantean una gama de actividades propias de los periodistas que trabajan en el campo digital lo que contribuye, de manera clara, a entender el proceso de transformación en lo referente al medio para el que se trabaja y, por supuesto, partiendo de la premisa que la audiencia es netamente cibernética.

\section{Metodología}

Esta investigación describe la forma cómo los periodistas de los diarios objeto de estudio usan Twitter para publicar contenido científico y el tratamiento dado a la información. Los periodistas de los diarios El Nacional y El Universal fueron seleccionados para esta investigación al ser los más antiguos de Venezuela. Para ello, se analizan los tuits publicados durante septiembre y octubre de 2014 de las periodistas de El Nacional y El Universal que cubren la fuente ciencia y tecnología. La periodista de El Nacional registra 125 tuits y la periodista de El Universal publica 100 tuits. La población total es de 225 tuits relacionados con ciencia y tecnología. Más de la mitad del contenido publicado por la periodista de El Nacional es sobre ciencia y tecnología (Tabla 1).

Tabla 1. Número de tuits sobre ciencia y tecnología de las periodistas de El Nacional y El Universal (septiembre-octubre 2014). Elaboración propia, 2016

\begin{tabular}{|r|c|c|}
\hline \multicolumn{1}{|c|}{ Medio } & Número de tuits & $\begin{array}{c}\text { Tuits sobre ciencia } \\
\text { y tecnología }\end{array}$ \\
\hline Periodista El Nacional & 264 & 125 \\
\hline Periodista El Universal & 824 & 100 \\
\hline Total & 1088 & 225 \\
\hline
\end{tabular}


En esta investigación se toma como muestra los tuits que tienen relación con cualquier área de la ciencia, tecnología y afines. El tipo de muestreo es intencional. Los criterios de selección de la muestra son: periodistas venezolanas y trabajar o haber trabajado en los diarios objeto de estudio durante los meses en que se realiza la investigación. Las técnicas usadas son la observación y la entrevista. Se diseñaron dos instrumentos de recolección de información, uno para la observación y otro para la entrevista.

Las categorías de análisis son las siguientes:

a) Áreas de la ciencia: Medicina, Ambiente, Astronomía, Tecnología, Economía, Educación, Biología, Deportes, Matemáticas, Física, Química, Política, Otros.

b) Procedencia: Agencias informativas, Información regional, Información nacional, Información internacional.

c) Actualidad: actualización constante.

d) Lenguaje: periodístico, científico o coloquial.

e) Fuentes: Gubernamental, Institucional, Universidades, Ciudadanos.

f) Hipertextualidad.

g) Multimedialidad.

h) Géneros periodísticos.

i) Funciones del periodismo.

\section{Análisis de resultados}

Al realizar el análisis a los tuits publicados por las periodistas de El Nacional y El Universal en sus cuentas en Twitter se logra comprobar que el 20,68\% del total de los tuits durante los meses del estudio, tienen como fin informar sobre ciencia. La periodista de El Nacional publica un promedio de 9 veces por día y 16 veces para la periodista de El Universal. Aunque usan la red social todos los días, algunas veces sólo se dedican a leer (según contestaron en la entrevista) y a retuitear a otros usuarios.

\subsection{Periodista El Nacional}

1. $47 \%$ de los tuits publicados de la periodista de El Nacional están relacionados con información científica. Se logra visualizar la importancia que la comunicadora le da a la información de índole científico.

2. $85 \%$ de la información son temas sobre Medicina. Los temas abordados fueron: búsqueda de medicamentos, denuncias en materia sanitaria, aparición del virus Chikunguña y control sobre el virus del Ébola en África.

3. Al analizar los enlaces se determina que el $58 \%$ de los tuits publicados por la periodista tiene por función informar. En el caso de los tuits en que no existen enlaces se determina, a través del análisis que forman parte de las opiniones emitidas por la periodista o provenientes de otras cuentas. Un $7 \%$ de los tuits con enlaces hacen parte de este tipo de divulgación de la ciencia.

4. En un $52 \%$ de los casos recurre a los ciudadanos para informar sobre estos asuntos. Un $6 \%$ equivale a la fuente gubernamental. 
5. 56\% de los casos procede del ámbito nacional. Se sitúa más en la zona central del país, en el Distrito Capital de Venezuela. Asimismo, un 30\% de la información procede de otros estados. Esto sugiere, ciertamente, que el $86 \%$ de las noticias en materia de ciencia emergen en todo el territorio nacional, en contraste un $14 \%$ se da a nivel internacional, dividiéndose éste en un $10 \%$ de procedencia internacional y un $4 \%$ también internacional con la característica de que surgen en agencias informativas.

6. $78 \%$ de los tuits son redactados en un lenguaje periodístico, entendible al lector. También se muestra un crecimiento en el uso de un lenguaje mixto, un $19 \%$ de los tuits iban con palabras usadas en el lenguaje formal, acompañadas de redacción informal. En los tuits se evidencia el uso de diversas maneras de escribir el lenguaje, ya que es un medio con características interactivas y dialógicas.

7. $69 \%$ de la información pertenece a la categoría "otro género periodístico". El 26\% de la información pertenece al género noticia, el 5\% restante se reparte entre la entrevista y el reportaje.

8. $44 \%$ son tuits tipo denuncias. Destacan los casos: falta de insumos en hospitales, carencia de medicamentos en las farmacias del país, hermetismo por parte de las autoridades en cuanto a la aparición de una extraña enfermedad en el Hospital Central de Maracay (estado Aragua), virus del Chikunguña, falta de control ambiental para erradicar enfermedades de contagio viral y la eliminación del Ministerio del Ambiente por parte del Gobierno venezolano.

9. Surgen los "Servicios Públicos" como modalidad ciudadana. Un 38\% de los tuits que la periodista publica tienen esta característica, acompañada de una etiqueta como \#ServPúblico para identificar que se trata de información de carácter científico, pues se refiere a la Medicina, pero también social, pues su fin es ayudar a ciudadanos enfermos a conseguir los medicamentos que necesitan para continuar algún tratamiento.

10. En un $88 \%$ de los casos la periodista no usa las funciones multimedia de la red social. En un $12 \%$ se observa el uso de las herramientas multimedia.

11. Las características multimedia de la red social las usa en un $12 \%$. El $11 \%$ de la multimedialidad se basa en el uso de imágenes planas y sólo 1\% en video.

12. $50 \%$ de los casos los tuits emitidos por la periodista tienen dos de las cuatro categorías que se presentan, de dicho porcentaje, un 35\% contienen enlaces. Asimismo, el $20 \%$ del total de los casos cuenta con tres categorías de las que se plantean en la gráfica, de ellas un $7 \%$ son enlaces. Un $19 \%$ son tuits que son retuiteados únicamente, sin que haya ninguna otra categoría.

13. $92 \%$ de la información observada era de carácter actual, es decir, estaba determinada por hechos que se suscitaban en lugares y tiempos precisos.

\subsection{Periodista El Universal}

1. La periodista dedica un $12 \%$ del total de sus tuits para informar sobre aspectos relacionados con la ciencia. En contraste con un $88 \%$ de información general más ligada a los temas y problemas políticos por los que atraviesa el país. 
2. $83 \%$ del contenido está relacionado con la Medicina. Casos: virus Chikunguya, escasez de medicamentos, entre otras. Destaca de modo positivo la información en otras áreas de la ciencia como la economía y el ambiente con un $5 \%$ de cobertura cada una.

3. La periodista limita sus tuits a compartir información relacionada con algún área de la ciencia. En un 18\% opina sobre la situación de la salud en el país y la falta de medicamentos. Sólo un $7 \%$ de sus tuits son destinados concretamente a la divulgación de información científica.

4. La mayor parte de la información sobre ciencia proviene de los ciudadanos y está relacionada con la búsqueda de medicamentos. Un $44 \%$ de los tuits toma como fuente información de índole ciudadana, un $42 \%$ de los casos con instituciones u organismos no gubernamentales y un 14\% de los tuits tienen como fuente al Gobierno.

5. En un $51 \%$ de los casos, el tuit tiene una procedencia nacional, el otro $49 \%$ se distribuye casi equitativamente entre información de procedencia extranjera y regional con un $24 \%$ y un $23 \%$ respectivamente.

6. $66 \%$ de los casos usa lenguaje común, sin embargo, se nota en el $31 \%$ el empleo de una terminología mixta, es decir, la mezcla del lenguaje técnico y coloquial para que la información de índole científica no quede mutilada de ninguna forma y los lectores puedan irse formando en términos de carácter científico-técnico.

7. $53 \%$ información está relacionada con otros géneros periodísticos. Un $30 \%$ de los tuits emitidos o retuiteados pertenecen a la noticia periodística a la que se logra acceder debido a la característica del enlace que dirige a la página del diario que publica la nota y un $17 \%$ son reportajes.

8. $51 \%$ de los tuits emitidos o retuiteados son servicios públicos, ello con el objeto de ayudar a los ciudadanos en la búsqueda de fármacos.

9. $85 \%$ de los casos estudiados no usa la característica multimedia de la red social para ayudar a los lectores a comprender la información sobre ciencia. Solamente el $15 \%$ de los tuits está acompañado del uso de contenido visual o auditivo.

10. $15 \%$ de multimedialidad. El contenido sólo cuenta con el uso de imágenes, perdiéndose así la posibilidad del vídeo o pistas de audios. Un $85 \%$ se mantiene, como en la gráfica anterior, sin contenido multimedia.

11. $37 \%$ de los tuits analizados obtienen por lo menos tres categorías de las anteriores, lo que permite que haya interactividad en red. Muy seguido está el uso de sólo dos categorías con un 32\% y todas las categorías en un $21 \%$.

12. $98 \%$ de los tuits estudiados tienen información signada por la actualidad. De esta manera queda claro que parte del tratamiento informativo dado a la información científica y tecnológica debe estar marcada por la actualidad.

A partir de las entrevistas se consiguieron los siguientes resultados:

Área temática: uso de Twitter

1. Ambas periodistas dejan claro que su cuenta es para uso personal y así lo reflejan, incluso, en la misma red social. Por lo tanto, no se limitan a tuitear sobre la fuente que cubren en sus lugares de trabajo. Sus publicaciones 
comprenden temas políticos, literatura y cine. En este punto, las periodistas coinciden en que usan la plataforma para informarse, seguir a otros usuarios y compartir opiniones.

2. La publicación de información por parte de las periodistas es muy variada. La mayoría de sus tuits no tienen contenido con información científica o tecnológica. Una de las periodistas contesta que decide retuitear opiniones para que los usuarios que la siguen tengan la oportunidad de leer lo mismo que ella sin que esta esté de acuerdo con lo que se publica. La publicación de información está más ligada al acontecer noticioso en el país, a opinar, denunciar y ayudar en la búsqueda de medicamentos, lo que se ha denominado servicio público.

3. Informarse: ambas periodistas coinciden en que una buena parte del tiempo en la red social lo aplica para informarse, por supuesto, desde fuentes confiables para no caer en la especulación.

4. Las entrevistadas concuerdan en esta arista en particular, uno de las virtudes de la red social es que los usuarios pueden seguir sus cuentas favoritas, artistas, instituciones políticas, científicas, religiosas, ciudadanos. De hecho, el primer contacto que se hace con las periodistas que se estudian en este trabajo es a través del Twitter, gracias a esa herramienta de seguir cuentas.

5. Retuitear información. Un gran porcentaje de su tiempo en la red es para retuitear noticias, informaciones u opiniones de cualquier temática o índole, no limitan este beneficio a la actividad científica.

6. En este punto particular, la frecuencia con la que las periodistas utilizan la red social es muy difícil de medir o predecir. Se limitan a responder que lo hacen varias veces al día o todo el día. No hay un patrón definido para el uso por ninguna de ellas.

7. Ambas coinciden en que sí publican algunas de las notas que cubren en el diario para el que trabajan. La periodista de El Nacional dedica un poco más de su tiempo en Twitter para publicar sus noticias relacionadas con la fuente salud pública, mientras que la periodista de El Universal señala que tuitea o retuitea sobre reportajes de profundidad e investigación.

8. En este punto es importante señalar que el acontecer venezolano, sobre todo desde el ámbito político es muy movido, los temas de esta índole se consumen la mayor cantidad de tuits que los periodistas emiten, ciertamente de actualidad, estos acaparan la atención de las redactoras que dan prioridad a esta información y dejan de lado, en gran medida, las noticias de carácter científico.

9. Parte del uso que hacen de Twitter es para emitir opiniones personales, publicar sobre sus gustos musicales, pasatiempos, denuncias ciudadanas, estado del tránsito y lo que están escuchando.

10. Ambas periodistas muestran acuerdos en que Twitter es una herramienta que no es indispensable para el periodismo, es necesaria pero no indispensable. No todo debe convertirse en periodismo de Twitter pues es imperioso el contacto directo con las fuentes informativas. Están claras en que no todo lo que se publica en la red social es veraz.

Las periodistas coincidieron en los temas, fuente, cobertura periodística nacional, lenguaje, función y actualidad (Tabla 2). 
Tabla 2. Coincidencias en el contenido de las periodistas de El Nacional y El Universal (septiembre-octubre 2014). Elaboración propia, 2016

\begin{tabular}{|l|l|}
\hline \multicolumn{1}{|c|}{ Coincidencias por áreas } & \multicolumn{1}{c|}{ Análisis } \\
\hline Temas de ciencia y tecnología: Medicina y salud & $\begin{array}{l}\text { Más del } 80 \% \text { del contenido tuiteado por ambas } \\
\text { periodistas se refiere a la Medicina }\end{array}$ \\
\hline Fuente informativa: ciudadanos & $\begin{array}{l}\text { Domina la fuente ciudadanos casi un } 50 \% \text { para } \\
\text { ambas periodistas }\end{array}$ \\
\hline Cobertura periodística: Nacional & $\begin{array}{l}\text { Casi el } 50 \% \text { del contenido da cobertura al } \\
\text { ámbito nacional }\end{array}$ \\
\hline Lenguaje: coloquial & $\begin{array}{l}\text { Más del } 60 \% \text { del contenido es publicado con un } \\
\text { lenguaje coloquial }\end{array}$ \\
\hline Función: servicio público o denuncia & $\begin{array}{l}\text { Más del } 50 \% \text { del contenido de las periodistas es } \\
\text { para solicitar medicamentos o para denunciar } \\
\text { problemas del sector salud }\end{array}$ \\
\hline Actualidad: constante & $\begin{array}{l}\text { Más del } 90 \% \text { del contenido publicado se refiere } \\
\text { a temas actuales }\end{array}$ \\
\hline
\end{tabular}

\section{Conclusiones}

La ciencia y la tecnología son un fundamento importante de la herencia social-cultural y por lo tanto sujeta al quehacer político-económico. El periodismo científico en Venezuela debería contribuir con el desarrollo de espacios posibles para difundir información científica-tecnológica, y un periodismo, que logre entender el potencial que poseen las redes sociales como ese medio de divulgación que no sólo permitiría la lectura de temas de la ciencia actual, sino la interactividad con las audiencias.

Dado el avance que en materia de ciencia y tecnología reina en la sociedad moderna, el periodismo científico trabaja en contribuir con una cultura que promueva la evolución y mejora de la colectividad, es así como sin dejar de lado la forma tradicional del ejercicio de la profesión se arriesga a entrar a plataformas tecnológicas que sirven para llegar a un buen número de lectores o usuarios en redes sociales de comunicación.

La interactividad de las redes sociales hace que aparezca en el panorama periodístico venezolanos dos "géneros" que aunque no lo sean propiamente forman parte de los resultados de esta investigación. Ellos son: el servicio público y la denuncia. Esto lo realizan los periodistas a través de sus cuentas en la red social, bien sean mensajes tuiteados por ellos o retuiteando a algún otro usuario.

La información en materia sanitaria, según el análisis realizado, está por encima del $80 \%$ con respecto a los tuits estudiados que se relacionan con la ciencia, por lo que, se asume que existe presencia de información científica en la que solo se da cobertura a un aspecto de la misma (la salud) dando poca importancia a temas relacionados con la tecnología, el ambiente, entre otros.

Es así como el uso de Twitter por parte de los periodistas que cubren la fuente científica en los dos más antiguos periódicos a nivel nacional es utilizado en más del $75 \%$ en ambos casos estudiados para opinar o informar sobre otros aspectos del itinerario venezolano. Sólo un poco más del $20 \%$ de los tuits estudiados informa, opina o muestra algún tipo de contenido relacionado con el ámbito científico. 


\section{Referencias bibliográficas}

Alconchel, Gabriel (2013): "Redes sociales y ciberpolítica: Twitter y el debate sobre el estado de la nación”. [Documento en línea] Tesis para optar al título de máster en Comunicación y Cultura, Universidad de Sevilla. En:

http://fama2.us.es/fco/tmaster/tmaster41.pdf [Consulta: 10 de noviembre de 2015]

Antón, Margarita y Alonso, Estrella (2015): "El 'trending topic' frente a la 'agenda setting"”. Estudios sobre el Mensaje Periodístico, 21, Núm. especial diciembre, 23-34. Madrid, Ediciones Complutense, en:

http://revistas.ucm.es/index.php/ESMP/article/view/51125/47465 [Consulta: 2 de enero de 2016]

Calvo Hernando, Manuel (1997): "Manual de Periodismo Cientifico". Barcelona, Bosch.

Cazaux, Diana (2010): "La comunicación de la ciencia y la tecnología en América Latina". Anuario Electrónico de Estudios en Comunicación Social "Disertaciones", 3 (2), Artículo 1: http://erevistas.saber.ula.ve/index.php/Disertaciones/ [Consulta: 31 de mayo de 2015]

Chirinos, Exequíades y Torres, Lina (2013): "Ciberperiodista: nueva profesión en Venezuela". [Documento en línea] Ponencia presentada en el IV Congreso de Investigadores de la Comunicación. Barquisimeto, Venezuela, en:

saber.ucv.ve/jspui/bitstream/.../235010092-Memoria-Invecom-2013.pdf [Consulta: 22 de abril de 2015]

Cobos, Tania (2010): “Twitter como fuente para periodistas latinoamericanos". Revista "Razón y Palabra”: En:

http://www.Razónypalabra.org.mx/N/N73/Varia 73/33Cobos_V73.pdf [Consulta: 8 de febrero de 2015]

Delclós, Tomás (2008): “Míster Twitter”, en El País, 17 de enero, sección Tecnología: http:// elpais.com/diario/2008/01/17/ciberpais/1200540265_850215.html [Consulta: 5 de enero de 2016]

Ferrer, Argelia (2003): "Periodismo Cientifico y Desarrollo. Una mirada desde América Latina”. Mérida, Venezuela, Ediciones del Rectorado.

García, Antonio y Fernández, René (2011): “Difusión y divulgación científica en Internet”. España, Adama Web S.L, p. 114.

Gregori, Javier (2004): “El Periodismo Científico, Hoy”. Revista QUARK, 34, en: http:// quark.prbb.org/34/034027.pdf [Consulta: 27 de diciembre de 2014]

Harris, Andrea; Ríos, Omaira; y Páez, Ángel (2011): "El periodista venezolano en Twitter". Anuario Electrónico de Estudios en Comunicación Social "Disertaciones", 4 (2), Artículo 6: http://erevistas.saber.ula.ve/index.php/Disertaciones/ [Consulta: 16 de julio de 2015]

Herrero-Curiel, Eva (2012): "El periodismo en el siglo de las redes sociales". Revista de Comunicación Vivat Academia, en:

http://pendientedemigracion.ucm.es/info/vivataca/numeros/n117E/PDFs/EHerre.pdf [Consulta: 6 de febrero de 2015]

Lozares, Carlos (1996): "La teoría de redes sociales". Papers, revista de Sociología, 48, 103-126. Barcelona, Universidad Autónoma de Barcelona. Barcelona, Departamento de Sociología. [http://dx.doi.org/10.5565/rev/papers/v48n0.1814]

Noguera, José (2010): "Redes sociales como paradigma periodístico. Medios españoles en Facebook". Revista Latina de Comunicación Social, 65, 176-186. La Laguna (Tenerife), Universidad de La Laguna, en:

http://www.revistalatinacs.org/10/art/891_UCAM/13_JM_Noguera.html [Consulta: 2 de diciembre de 2015] 
Pérez, Víctor (2007): “Algunos aspectos deontológicos en la cobertura de informaciones científicas Estudio de caso: Crisis volcánica” del Teide”. Revista Latina de Comunicación Social, 62, en:

http://www.ull.es/publicaciones/latina/200709Perez_Martinez.htm_ [Consulta: 25 de abril de 2015]

Ponce, Isabel (2012): "Monográfico: Redes Sociales". Observatorio Tecnológico del Gobierno de España, en.:

http://recursostic.educacion.es/observatorio/web/es/internet/web-20/1043-redes- sociales [Consulta: 5 de febrero de 2015]

Quiñónez, Herly (2015): "Enseñanza de la escritura digital: aspectos formativos para el periodismo científico". Revista Educere. Año 19, 63, mayo-agosto, en:

http://www.redalyc.org/pdf/356/35643049006.pdf [Consulta: 5 de diciembre de 2015]

Zamarra, María Mercedes (2015): “Análisis de los diarios digitales españoles más influyentes y su presencia en las redes sociales”. Estudios sobre el Mensaje Periodístico, 21, Núm. especial diciembre, 155-170. Madrid, Ediciones Complutense, en: http://revistas.ucm.es/ index.php/ESMP/article/view/51137/47475 [Consulta: 3 de enero de 2016]

Herly Alejandra Quiñónez Gómez es Comunicadora Social, profesora e investigadora de la Universidad de Los Andes en Venezuela. Miembro del Grupo de investigación "Comunicación, Cultura y Sociedad". Cursa estudios de Doctorado en Ciencias Humanas en la Universidad de Los Andes en Venezuela.

Moisés Francisco Sánchez Colmenares es Comunicador Social de la Universidad de Los Andes en Venezuela. Departamento de Comunicación Social. 